Anthony, W. (1993) Recovery from illness. The guiding vision of the mental health service systems in the 1990s. Psychosocial Rehabilitation Journal, 16, 11-23.

Antonovsky, A. (1987) Unraveling the Mystery of Health. Jossey-Bass.

Beauchamp, T. \& Childress, J. (1994) Principles of Biomedical Ethics (4th edn). Oxford University Press.

Bloch, S. (2005) The art of psychiatry. World Psychiatry, 4, 130-134. Christodoulou, G. N. (ed.) (1987) Psychosomatic Medicine. Plenum Press.

Cloninger, C. R. (2004) Feeling Good: The Science of Well-Being. Oxford University Press.

Cox, J., Campbell, A. V. \& Fulford, K. W. M. (eds) (2006) Medicine of the Person: Faith, Science and Values in Health Care Provision. Jessica Kingsley Publishers.

Department of Health (2005a) New Ways of Working for Psychiatrists: Enhancing Effective, Person-Centred Services Through New Ways of Working in Multidisciplinary and Multiagency Contexts (Final report 'but not the end of the story'). Department of Health.

Department of Health (2005b) Independence, Well-Being and Choice: Our Vision for the Future of Social Care for Adults in England. Department of Health.

Department of Health (2005c) Creating a Patient-Led NHS: Delivering the NHS Improvement Plan. Department of Health.

Fulford, K. W. M., Ersser, S. \& Hope, T. (eds) (1995) Essential Practice in Patient-Centred Care. Blackwell Science.

Fulford, K. W. M., Dickenson, D. \& Murray, T. H. (eds) (2002) Healthcare Ethics and Human Values. An Introductory Text with Readings and Case Studies. Blackwell.

Herrman, I. T., Saxena, S. \& Moodie, R. (eds) (2005) Promoting Mental Health: Concepts, Emerging Evidence, Practice. World Health Organization.
Jouanna, J. (1999) Hippocrates (trans. M. B. Debevoise). Johns Hopkins University Press.

Mezzich, J. E. (2005) Positive health: conceptual place, dimensions and implications. Psychopathology, 38, 177-179.

Mezzich, J. E. (2007a) Psychiatry for the person: articulating medicine's science and humanism. World Psychiatry, 6, 1-3.

Mezzich, J. E. (2007b) The dialogal bases of our profession: psychiatry with the person. World Psychiatry, 6, 129-130.

Mezzich, J. E. \& Salloum, I. M. (2007) Towards innovative international classification and diagnostic systems: ICD-11 and person-centered integrative diagnosis. Acta Psychiatrica Scandinavica, 116, 1-5.

Office of the Surgeon General (1999) Mental Health: A Report of the Surgeon General. Department of Health and Human Services, US Public Health Service.

Patwardhan, B., Warude, D., Pushpangadan, P., et al (2005) Ayurveda and traditional Chinese medicine: a comparative overview. EvidenceBased Complementary and Alternative Medicine, 2, 465-473.

Presidential Commission on Mental Health (2003) Achieving the Promise: Transforming Mental Health Care in America. Final Report. DHHS Pub N: SMA-03-3832. Department of Health and Human Services.

Ricoeur, P. (1990) Time and Narrative. University of Chicago Press.

Sensky, T. (1990) Patients' reactions to illness. BMJ, 300, 622-623.

Sharfstein, S. S. (2005) Presidential address. Advocacy of our patients and our profession. American Journal of Psychiatry, 162, 2045-2047.

Strauss, J. S. (1992) The person - key to understanding mental illness. Towards a new dynamic psychiatry, III. British Journal of Psychiatry, 161 (suppl. 18), 19-26.

WHO European Ministerial Conference on Mental Health (2005) Mental Health Action Plan for Europe: Facing the Challenges, Building Solutions. Helsinki, Finland, 12-15 January 2005. EUR/04/5047810/7

\title{
European service perspectives for people with intellectual disabilities and mental health problems
}

\section{Geraldine Holt, ${ }^{1}$ Helen Costello ${ }^{2}$ and Nick Bouras ${ }^{3}$}

\begin{abstract}
${ }^{1}$ Consultant Psychiatrist, King's College London, Institute of Psychiatry, Estia Centre, London, UK, geraldine.holt@kcl.ac.uk ${ }^{2}$ Research Coordinator, King's College London, Institute of Psychiatry, Estia Centre, London, UK, email helen.costello@kcl.ac.uk ${ }^{3}$ Professor of Psychiatry, King's College London, Institute of Psychiatry, Estia Centre, London, UK, email Nick.Bouras@kcl.ac.uk
\end{abstract}

Suk ervices for people with intellectual disabilities, in the UK as elsewhere, have changed dramatically over the last 30 years; deinstitutionalisation has probably been the largest experiment in social policy in our time. The vast majority of people with intellectual disabilities, their families and carers have benefited from having a better quality of life as a result of deinstitutionalisation. However, much still needs to be done to integrate this population more into society and to ensure they are offered the appropriate supports to meet their needs.

There has been considerable variation nationally in the provision of services, particularly for those people with intellectual disabilities who have additional mental health problems. There is a relative lack of provision in some regions, despite the fact that evidence-based practice has shown that there is a high prevalence of undiagnosed and untreated mental disorder among people with intellectual disabilities. We also know that mental illness among people with intellectual disabilities often presents in atypical ways and that it may coexist with a wide range of neurodevelopmental disorders. Finally, we are aware that many people with intellectual disabilities have impaired communication and hence are unable to describe subjective symptoms; these individuals are particularly at risk of being overlooked or misdiagnosed.

Despite the uneven provision of services for people with intellectual disabilities, an international consensus has emerged and most countries have been trying to develop relevant policies and services for them. Although models of care are changing, the pace of change varies dramatically between countries. This issue's thematic papers provide an insight into services for people with intellectual disabilities and mental 
health problems in Greece, Austria and Switzerland. The three papers provide interesting comparisons.

In Greece, services have been undergoing radical reform in recent years, starting from a rather low base. An increasing number of community-based services and support schemes have been developed, while the proportion of the population with intellectual disabilities who were formerly confined to institutions has been greatly diminished. In Austria there are no national registers of intellectual disabilities, a state of affairs that has arisen partly for historic political reasons. Austria offers a dramatic example of how a country's history (in this case the close association with Nazi Germany) can shape its policies, legislation and services. New, supported community-based services have been developed away from the large psychiatric institutions. In contrast, in Switzerland most adults with intellectual disabilities seem to be still living in institutions, although some smaller community-based residential units have also been set up recently.

In all three of these European services there is a disparity for the provision of people with intellectual disabilities and mental health problems. The UK has also been struggling with this state of affairs. The assumption that mainstream psychiatric services are able to address the complex mental health needs of the heterogeneous population with intellectual disabilities is obviously flawed. Although evidence about the effectiveness of provision is limited, research suggests that some individuals with intellectual disabilities have particularly complex needs, which cannot be met as effectively or even as quickly by generic services as they could by specialised services (Xenitidis et al, 2004).

The need for specialist training for those professional workers who are supporting adults with intellectual disabilities and mental health problems is recognised in Greece, Austria and Switzerland. To be effective, these workers should aim to function within a policy framework that enables collaboration between the relevant agencies. There should be clear care pathways, so that service users, their supporters and service providers all understand the roles and responsibilities of different professionals (Holt et al, 2005).

We hope that with the emerging evidence base, these thematic papers will stimulate debate about how to institute a European initiative on planning effective services for people with intellectual disabilities and mental health problems.

\section{References}

Holt, G., Hardy, S. \& Bouras, N. (eds) (2005) Mental Health in Learning Disabilities: A Training Package for Staff Working with People with a Dual Diagnosis of Learning Disability and a Mental Health Problem (3rd edn). Pavilion Publishing.

Xenitidis, K., Gratsa, A., Bouras, N., et al (2004) Psychiatric inpatient care for adults with intellectual disabilities: generic or specialist units? Journal of Intellectual Disability Research, 48, 11-18.

\section{THEMATIC PAPER - EUROPEAN PERSPECTIVES ON INTELLECTUAL DISABILITY}

\section{Greece}

\section{Anastasia Karastergeriou MD PhD}

Consultant Psychiatrist, Psychiatric Hospital of Thessaloniki, Thessaloniki, Greece, email anakar@med.auth.gr

$$
T^{\text {hin }}
$$

he history of mental healthcare offered to people with intellectual disabilities in Greece runs in parallel to that of people suffering from severe psychiatric disorders. Until the early 1980s, it was based on 9 overcrowded and understaffed state and 40 private psychiatric hospitals with a mixed population of patients with psychosis and of those with intellectual disabilities (Madianos et al, 1999). The psychiatric reforms began with Law 1397 in 1983, which introduced the National Health System, and, in the following year, European Council Regulation 815/84, through which financial aid was approved and a 5-year plan adopted. The main goal was the development of a network of community-based services in geographically sectorised areas, to replace the large psychiatric hospitals. Mental health centres, psychiatric units in general hospitals and many other community services were to be established, according to local requirement.

The implementation of these plans was initially very slow. The exposure in 1989 of the distressing conditions in the Leros Mental Hospital, which had many patients with intellectual disabilities (Bouras et al, 1992), resulted in the rehousing of a large number of them to fully staffed community residential facilities near their areas of origin (Tsiantis, 1995). The original 5-year plan was extended to cover a whole decade, by the end of which the improvement of the infrastructure of mental health services was considerable and several pilot community projects had been developed, including staff training projects (Tsiantis et al, 2006). However, mental health sectors, the basic structural elements of the new community-based service system, had not been implemented and the desired network of services still had big gaps, leaving some regions without access to community psychiatric care, but instead with only the oldstyle psychiatric hospitals, although considerably transformed.

\section{National indicators of prevalence}

Intellectual disability is defined as significantly sub-average general functioning (IQ below 70), existing concurrently with deficits in adaptive behaviour, manifested during the developmental period. Eligibility for services is established by a local health committee and is based on medical diagnosis, a percentage disability rating and insurance status. Additionally, people with intellectual disabilities are eligible for all the services and benefits generally provided to people with disabilities, such as healthcare, vocational training, employment, housing, transportation and tax exemption (Pandeliadou, 2003).

Information on the prevalence of intellectual disability in Greece does not exist. 